\title{
Hábitos de desinfección de cubetas e impresiones dentales en Universidad Nacional Toribio Rodríguez de Mendoza
}

\section{Habits of disinfection of cubetas and dental impressions in Toribio Rodríguez de Mendoza National University}

\author{
Alfredo Martin López-Villa ${ }^{1}$
}

\section{RESUMEN}

El objetivo de la investigación fue describir los hábitos de desinfección de cubetas e impresiones dentales utilizados por los estudiantes de la Escuela Profesional de Estomatología de la Universidad Nacional Toribio Rodríguez de Mendoza en el año 2018. La muestra de estudio estuvo representado por 118 estudiantes, utilizándose la observación indirecta como técnica, a través de la encuesta, cuyo instrumento fue elaborado por el autor y tiene una estructura tipo Ficha de Escala constituida por 33 ítems, validado por juicio de expertos y la confiabilidad se realizó a través de la técnica de alpha de Cronbach, en la cual se obtuvo .9798, en tal sentido el indicado fue confiable y de fácil aplicación. Según los resultados el 1,7\% siempre utilizan medios químicos para desinfectar las cubetas, 7,6\% utilizan medios físicos para dicha acción; el 58,9\% nunca utilizan medios químicos para realizar la desinfección de impresiones dentales y el 45,2\% tampoco utilizan medios físicos. La conclusión principal es que en la Escuela de Estomatología de la Universidad Nacional Toribio Rodríguez de Mendoza de Amazonas los/as estudiantes en un $82,2 \%$ tienen hábitos negativos y solo el 17,8\% son positivos en relación a la desinfección de cubetas e impresiones dentales.

Palabras clave: Hábitos, desinfección, cubetas, impresiones dentales.

\begin{abstract}
The objective of the research was to describe the habits of disinfection of buckets and dental impressions used by the students of the Professional School of Stomatology of the National University "Toribio Rodríguez de Mendoza. The study sample was represented by 118 students, using indirect observation as a technique, through the survey, whose instrument was developed by the author and has a structure type Scale File consisting of 33 items, validated by expert judgment and the Reliability was carried out through the Cronbach alpha technique, in which .78 was obtained, in this sense the indicated was reliable and easy to apply. According to the results, $1.7 \%$ always use chemical means to disinfect the cuvettes, $7.6 \%$ use physical means for said action; $58.9 \%$ never use chemical means to disinfect dental impressions and $45.2 \%$ do not use physical means either. The main conclusion is that in the Stomatology School of the National University Toribio Rodríguez de Mendoza of Amazonas the students in $82.2 \%$ have negative habits and only $17.8 \%$ are positive in relation to the disinfection of buckets and dental impressions.
\end{abstract}

Keywords: Habits, disinfection, buckets, dental impressions.

'Bachiller en Estomatología; almalovi88@hotmail.com. 


\section{INTRODUCCIÓN}

El presente estudio es de suma importancia porque sirve como Término de referencia, la cual conlleva a analizar los hallazgos acerca de la falta de hábitos positivos de desinfección de cubetas e impresiones dentales por parte de los estudiantes de la Universidad Nacional Toribio Rodríguez de Mendoza que en cualquier momento pueden ocasionar contagios cruzados. Los docentes que enseñan en la Escuela profesional de Estomatología de la indicada Casa de Estudios y los estudiantes están potencialmente expuestos a adquirir enfermedades graves tales como la hepatitis B, C, el virus de la inmunodeficiencia humana y otros; sin embargo los docentes aún no toman las previsiones del caso incluso no hacen uso de los materiales de barrera, por consiguiente los estudiantes aun no toman conciencia sobre este particular. La desinfección de las cubetas y de las impresiones dentales son dispensables porque a través de ello se garantiza, en parte eliminar gran cantidad de microorganismos patógenos, esporas que se encuentran en los materiales. Se debe tener en cuenta que el realizar las desinfecciones es una práctica fundamental de la bioseguridad con la finalidad de evitar las infecciones cruzadas.

La desinfección de las impresiones dentales es un procedimiento clave para el control de la contaminación cruzada y la transmisión de microorganismos, sin embargo, existe poca información sobre la eficacia en el uso de métodos y técnicas de desinfección bajo condiciones clínicas. Comúnmente son utilizados desinfectantes químicos como: alcoholes, aldehídos, compuestos de cloro, compuestos fenólicos, compuestos de yodo y compuestos cuaternarios de amonio. Se ha demostrado que el enjuagar con agua corriente puede reducir la carga microbiana pero no desinfecta la impresión eficientemente, por lo cual deben ser utilizados métodos adicionales. Múltiples estudios sobre la utilización de desinfectantes químicos como es el caso del glutaraldehído al $2 \%$, considerado como un desinfectante eficaz en la eliminación de microorganismos presentes en impresiones dentales con materiales elásticos. Por otro lado, se debe tomar en cuenta que el procedimiento de desinfección ideal no debe cambiar las propiedades físicas ni químicas del material de impresión, ni al resultante en el modelo de yeso para lograr la precisión de la prótesis definitiva. (Kotsiomiti, et al., 2008, p. 291).

\section{MATERIAL Y MÉTODOS}

El objeto de estudio fue realizar una investigación acerca de los hábitos de desinfección de cubetas e impresiones dentales utilizados por los/as estudiantes de la Escuela Profesional de Estomatología, Universidad Nacional Toribio Rodríguez de Mendoza de Amazonas- 2018. Estuvo enmarcado dentro del enfoque cuantitativo; de nivel descriptivo; de tipo: según la intervención del investigador fue observacional; según la planificación de la toma de datos para la variable fue prospectivo; según el número de ocasiones en que se midió la variable fue no experimental de corte transversal; según el número de variables de interés fue univariado. (Supo, 2015, pp. 2 - 19). Al respecto Hernández, et al., (2010) indica que: "En la investigación no experimental no hay ni manipulación intencional, ni asignación al azar" (p.150) y que "Los diseños de investigación transversales recolectan datos en un solo momento, en un tiempo único; su propósito es describir variables y analizar su incidencia e interrelación en un momento dado" (p.151). En esta investigación se recogió los hallazgos en un solo momento y de ninguna manera se manipuló a los datos; en tal sentido se presentó los resultados tal como se encontraron en la realidad. La población considerada en esta investigación estuvo conformada por 154 estudiantes matriculados en el semestre 2018-01, de los cuales (102) que equivale al $66,22 \%$ al género femenino y (52) corresponde al 33,78\% al género masculino en la Escuela de Estomatología de la universidad Nacional Toribio Rodríguez de Mendoza de Amazonas en el año 2018. La muestra de estudio fue designada por conveniencia y más que todo de acuerdo a la voluntad de participación de los estudiantes sin embargo se tuvo en cuenta que estén cursando desde el II al X ciclo de estudios, por tanto se tuvo 118 participantes. Durante el proceso de la investigación se utilizó el método deductivo es decir que se partió de casos generales hasta realizar el estudio en la muestra de estudio. Para la recolección de los datos se utilizó la técnica de la observación a través de la encuesta cuyo instrumento fue un cuestionario con respuestas tipo Likert el cual estuvo constituido por 33 ítems, además fue elaborado por el Autor y validado por un grupo de expertos en cuanto a su contenido, cuya confiabilidad se realizó a través de la técnica de alpha de Cronbach, resultando ser confiable ya que se tuvo .979 el cual está por encima del parámetro que es .63, en tal sentido el indicado fue confiable y de fácil entendimiento para los participantes.

El procedimiento que se realizó para la recolección de los datos fue en primer lugar cursar un oficio al Decano de la Facultad de Ciencias de la Salud de la Universidad Nacional Toribio Rodríguez de Mendoza de Amazonas, 2018, solicitando permiso a fin de aplicar las encuestas a los estudiantes de la 
indicada Casa de Estudios. Seguidamente después de haber recibido la aceptación se visitó a los estudiantes en sus respectivas aulas, se les hizo conocer el propósito y luego de haber recibido la aceptación correspondiente en forma verbal se procedió a distribuir las Fichas de cuestionario, paralelamente se les indicó que lean cada ítem y que deben colocar un aspa (x) en donde crean conveniente, pidiéndoles que la tomen con seriedad y responsabilidad ya que las respuestas dadas serán exclusivamente para el trabajo de investigación y que no serán divulgadas.

\section{RESULTADOS}

En la investigación formaron parte de la muestra (77) mujeres que corresponde al $65,30 \%$ y (41) son varones que equivale a $34,47 \%$.

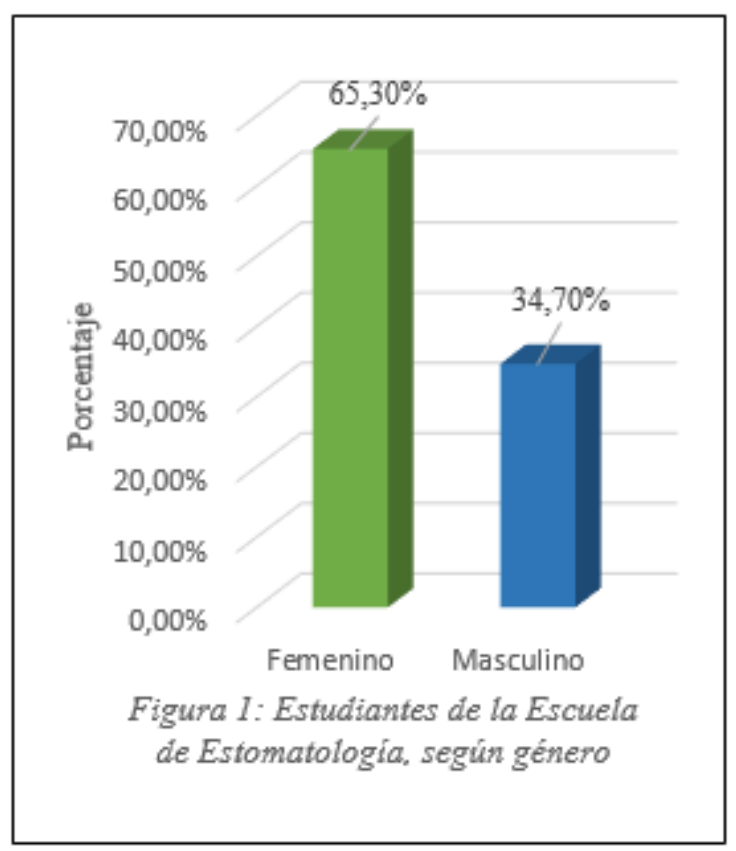

Tabla 01:

Medios físicos y químicos de desinfección de cubetas

\begin{tabular}{clcccc}
\hline \multirow{2}{*}{ Altemativas } & \multicolumn{2}{c}{ Quimicos } & \multicolumn{2}{c}{ Fisicos } \\
& fi & fi $\%$ & Fi & Fi\% \\
\hline Válido & Nunca & 1016 & $78.3 \%$ & 512 & $48.3 \%$ \\
& Casinunca & 104 & $8.0 \%$ & 179 & $16.9 \%$ \\
& A veces & 106 & $8.2 \%$ & 176 & $16.6 \%$ \\
Casisiempre & 50 & $3.9 \%$ & 113 & $10.7 \%$ \\
& Siempre & 22 & $1.7 \%$ & 81 & $7.6 \%$ \\
\cline { 2 - 6 } & Total & 1298 & 100.0 & 1061 & \\
\hline
\end{tabular}

En lo que corresponde a la desinfección de cubetas por medios químicos se tuvo que más predominó la alternativa nunca en un 78,3\% y solamente el 1,7\% corresponde a siempre. Similar tenemos al referirse a la utilización de medios físicos en la que un 48.3\% corresponde a la alternativa nunca y solamente el $7.6 \%$ siempre.

Tabla 02:

Medios físicos y químicos de desinfección de impresiones dentales.

\begin{tabular}{ccccc}
\hline \multirow{2}{*}{ Alternativas } & \multicolumn{2}{c}{ Químicos } & \multicolumn{2}{c}{ Fisic os } \\
& fi & fi\% & Fi & Fi\% \\
\hline Válido Nunca & 278 & $58.9 \%$ & 160 & $45.2 \%$ \\
Casinunca & 78 & $16.5 \%$ & 68 & $19.2 \%$ \\
A veces & 75 & $15.9 \%$ & 67 & $18.9 \%$ \\
Casisiempre & 23 & $4.9 \%$ & 36 & $10.2 \%$ \\
Siempre & 18 & $3.8 \%$ & 23 & $6.5 \%$ \\
\hline Total & 472 & $100.0 \%$ & 354 & $100.0 \%$ \\
\hline
\end{tabular}

En lo que corresponde a la desinfección de impresiones dentales por medios químicos se tuvo que más predominó la alternativa nunca en un $58,9 \%$ y solamente el 3,8\% corresponde a siempre. Similar tenemos al referirse a la utilización de medios físicos en la que un $45,2 \%$ corresponde a la alternativa nunca y solamente el $6,0 \%$ siempre.

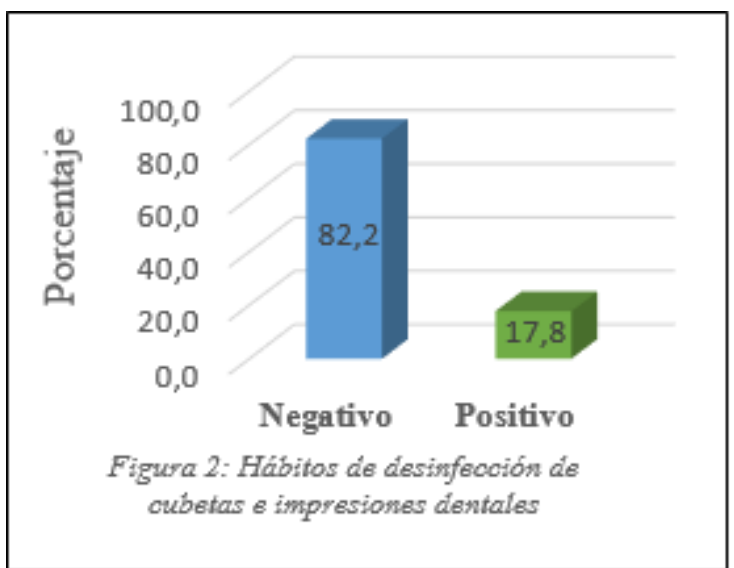

En forma general se tuvo que el $82,2 \%$ de los encuestados tienen hábitos negativos para la desinfección de cubetas e impresiones dentales y que solo el 17,8\% tienen hábitos positivos.

\section{DISCUSIÓN}

La desinfección de cubetas y modelos es uno de los procedimientos indefectibles que los profesionales de la salud, especialmente los/as que estudian la carrera de odontología deben tenerlo en cuenta con el fin de evitar la contaminación cruzada con los pacientes y con el medio donde se desarrollan o se forman para esta difícil e importante profesión, ya que están expuestos de adquirir enfermedades cruciales tales como la hepatitis B, que es lamentable.

Al respecto Cabezas (2008), en su artículo de revisión denominado Situación y Control de la hepatitis B y Delta en el Perú indica que: "La vacuna disponible contra HBV es eficaz y segura, y siendo la 
vacunación una de las intervenciones más efectivas, se han desarrollado programas de vacunación piloto en el país, con un significativo impacto sobre la tasa de infección; por lo que amerita ampliar la población objetivo a inmunizar, como son los adolescentes y jóvenes y grupos de riesgo de manera que se acorten los periodos para eliminar la infección por HBV y por tanto sus secuelas crónicas". En tal sentido es meritorio mencionar que los profesionales de la salud, específicamente los Odontólogos se encuentran en los grupos de riesgo, por tanto se debe realizar la prevención con la vacuna correspondiente; al respecto Esam et al., (2015) indica que el $71,7 \%$ de los estudiantes habían sido vacunados para la hepatitis B y solo el 9,5\% fueron evaluados para detectar la hepatitis B serología de inmunización viral, sin embargo en nuestro caso debido a la poca aplicación de desinfección de cubetas e impresiones dentales se presume una mayoría de estudiantes no inmunizados sobre este particular, dato que llama la atención y que es posible que con el tiempo desencadene dicha enfermedad.

En el estudio se tuvo que el $82,2 \%$ tienen hábitos negativos y el 17,8\% hábitos positivos con relación a la desinfección de cubetas e impresiones dentales; también tenemos un $24.6 \%$ que nunca desinfectan las cubetas después de utilizarlas. Estos datos llaman la atención y sirven de reflexión ya que estamos frente a casos de vulnerabilidad que en el futuro si es que no se toma las medidas correctivas y pertinentes estaremos ante cuadros lamentables, me refiero a masivos contagios cruzados por no tomar las previsiones del caso. En el estudio realizado por Maciel et. al., (2014), el 64,28\% de los entrevistados declararon realizar desinfección de las cubetas y el $35.72 \%$ no realiza, al comparar los resultados se tiene entonces que mayor prevención se tiene en los profesionales de consultorio particulares, esto quizás se deba a que los primeros resultados corresponden a profesionales y estos últimos a estudiantes.

En el estudio se encontró que el $11 \%$ de los estudiantes utilizan siempre el hipoclorito de sodio para la desinfección de las cubetas y los demás medios químicos no se les hace conocidos, estos datos tienen cierta similitud con las de Maciel et al., (2014), en la cual el 69,23\% de los profesionales utilizan también el indicado químico; en el estudio de Boas y Quirino (2002) se indica que el hipoclorito de sodio es el químico más utilizado para la desinfección, quizá se deba a que es el químico que hay más en el mercado o por lo que su costo es menor con relación a los demás.

El $43,9 \%$ de los encuestados del estudio a veces siempre utilizan guantes para desinfectar las cubetas e impresiones dentales, en cambio en el estudio realizado por Esam, et al., (2015) el (96.6\%) informaron que siempre usan guantes para todos los procedimientos dentales. En tal sentido es notorio que hay mayor sensibilización y cultura de protección por parte de éstos últimos. En tal sentido los profesores deben utilizar las estrategias necesarias y pertinentes a fin de que los estudiantes se habitúen a la utilización de los guantes porque en parte protege a los estudiantes cuando están realizando las prácticas de laboratorio.

En relación a la desinfección de impresiones dentales se tuvo que el $82,2 \%$ en lo que se refiere a hábitos de desinfección se encuentran en negativo y que $51,7 \%$ de los/as estudiantes encuestados nunca realizan la desinfección de las impresiones dentales en cambio en el trabajo de investigación realizado por Sakshi, et al., (2017), el 30.76\% de los técnicos dentales desinfectan todas las impresiones y el $67.30 \%$ de los técnicos usan inmersión para la desinfección de impresiones. Solo el 38.46\% respondieron que sumergían impresiones por 10 minutos para la desinfección.

Teniendo en cuenta los resultados obtenidos en la presente investigación es meritorio considerar que los mismos deben servir como términos de referencia a fin de que las autoridades de la UNTRM tomen cartas en el asunto y propicien reglas a fin de que los/as estudiantes de la Carrera Profesional de Odontología desde los primeros ciclos de estudios demuestren estar vacunados contra la hepatitis B y así evitar focos infecciosos, y más que todo se evite las contaminaciones cruzadas; además es meritorio que los docentes de la indicada Casa de Estudios en los momentos que realizan las prácticas de laboratorio sean los que dan el ejemplo utilizando los medios de barrera (guantes) con el fin de que los/as estudiantes se habitúen y no cometan errores que después lamenten.

En tal sentido es importante que a nivel de Escuela de Estomatología de la UNTRM se plantee y/o formule un protocolo que ayude a los/as estudiantes empoderarse de hábitos positivos de desinfección tanto de cubetas como de impresiones dentales a fin de evitar los contagios cruzados, ya que en primer lugar se debe cuidar en todos los aspectos y niveles al ser humano, por tanto estamos de acuerdo con el Modelo de motivación a la protección planteado por Rogers (1975) y reformulado por Rippetoe y Rogers (1987); es decir que los/as estudiantes deben cultivar una cultura de protección a fin de evitar ser contagiados. 


\section{CONCLUSIONES}

En la Escuela de Estomatología de la Universidad Nacional Toribio Rodríguez de Mendoza de Amazonas, los/as estudiantes en un $82,2 \%$ tienen hábitos negativos y solo el $17,8 \%$ son positivos en relación a la desinfección de cubetas e impresiones dentales; el 78,3\% nunca utilizan medios químicos para la desinfección de cubetas y solo el $1,7 \%$ siempre lo tienen en cuenta; el 48,3\% nunca utilizan medios físicos para la desinfección de cubetas y solo el 7,6\% siempre utilizan dicho medio; el 58,9\% nunca utilizan medios químicos para la desinfección de impresiones dentales y solamente el 3,8\% siempre utilizan dicho medio; el 45,2\% nunca utilizan medios físicos para la desinfección de impresiones dentales y solamente el 6,5\% siempre utilizan dicho medio.

\section{BIBLIOGRAFÍA}

Cabezas, C. (2008). Situación y control de la hepatitis B y Delta en el Perú. Acta Med Per 25 (02). Perú

Hernández, R., Fernández, C., Baptista, P. (2010). Metodología de la investigación. 5 ta. ed.

Maciel-Pereira, D., Romero-de Souza Gil, F., De Landa, F., Goulart-Cruz, F., MoralesVadillo, R., \& Dos Reis Goyata, F. (2014). Desinfección de cubetas y modelos. Aplicación de Bioseguridad en la Práctica Clínica Particular. Revista $\mathrm{S}$ a $1 \mathrm{ud}, 11$ ( 1 ), p p.4649.Obtenidodehttp://www.usmp.edu.pe/ odonto/servicio/2014/kiru_v11/Kiru_v.1 1_Art.7.pdf.

Esam, Sadeq, Aisha, Bassel, Walid. (2015). Knowledge, Attitudes, and Practice of Infection Control among Dental Students at Sana'a University, Yemen. Disponible e $\mathrm{n}$

https://www.ncbi.nlm.nih.gov/pmc/articl es/PMC4441229/

Kotsiomiti E, Tzialla A, Hatjivasiliou K. (2008). Accuracy and stability of impression materials subjected to chemical disinfection - a literature review. J Oral Rehabil. 2008; 35: 291-299. Disponible e $\mathrm{n}$ www.dental.theclinics.com/article/S001 1 ...8/references 